\title{
Thyroid Hormone and Cardiac Disease: From Basic Concepts to Clinical Application
}

\author{
Iordanis Mourouzis, ${ }^{1}$ Francesca Forini, ${ }^{2}$ Constantinos Pantos, ${ }^{1}$ and Giorgio Iervasi ${ }^{2}$ \\ ${ }^{1}$ Department of Pharmacology, University of Athens, 11527 Athens, Greece \\ ${ }^{2}$ CNR Institute of Clinical Physiology and Fondazione CNR-Regione Toscana G. Monasterio, Pisa, Italy
}

Correspondence should be addressed to Giorgio Iervasi, iervasi@ifc.cnr.it

Received 11 January 2011; Revised 16 March 2011; Accepted 20 March 2011

Academic Editor: Michelina Plateroti

Copyright (c) 2011 Iordanis Mourouzis et al. This is an open access article distributed under the Creative Commons Attribution License, which permits unrestricted use, distribution, and reproduction in any medium, provided the original work is properly cited.

\begin{abstract}
Nature's models of regeneration provide substantial evidence that a natural healing process may exist in the heart. Analogies existing between the damaged myocardium and the developing heart strongly indicate that regulatory factors which drive embryonic heart development may also control aspects of heart regeneration. In this context, thyroid hormone (TH) which is critical in heart maturation during development appears to have a reparative role in adult life. Thus, changes in TH -thyroid hormone receptor (TR) homeostasis are shown to govern the return of the damaged myocardium to the fetal phenotype. Accordingly, thyroid hormone treatment preferentially rebuilds the injured myocardium by reactivating developmental gene programming. Clinical data provide further support to this experimental evidence and changes in TH levels and in particular a reduction of biologically active triiodothyronine (T3) in plasma after myocardial infarction or during evolution of heart failure, are strongly correlated with patients morbidity and mortality. The potential of TH to regenerate a diseased heart has now been testing in patients with acute myocardial infarction in a phase II, randomized, double blind, placebo-controlled study (the THiRST study).
\end{abstract}

\section{Introduction}

The recognition of analogies between developmental processes and changes occurring in the damaged myocardium has refocused research on the pathophysiology of cardiac disease. In fact, divergent environmental stressful stimuli as pressure overload, hypoxia, ischaemia, metabolic disturbances, and so forth, seem to induce a common response of the heart which is characterized by the suppression of the postnatal gene program, resulting in the predominance of the fetal gene programming. The developmental switch of the diseased myocardium is not fully understood and much controversy surrounds this issue [1]. However, recent research provides evidence that reactivation of the fetal phenotype which leads to cell dedifferentiation may constitute a permissive state for regeneration. In this context, developmental regulators of cell differentiation/cell dedifferentiation process, such as thyroid hormone $(\mathrm{TH})$, may be implicated in this response with important therapeutic potentials [2]. In fact, there is accumulating evidence that TH while having a critical role during development may serve a regenerative/reparative role during adult life $[2,3]$. With this evidence in mind, this paper will highlight the basic concepts on the role of TH in the pathophysiology of heart disease with emphasis in the ischaemic heart disease and the potential clinical applications.

\section{Cardiac Remodeling: Reactivation of the Fetal Phenotype}

Cardiac remodeling is a stress response process to an index event such as ischaemia, mechanical loading, and metabolic alterations. Early in this process, a variety of compensatory mechanisms are in operation, such as activation of the inflammatory and neuro-hormonal systems. In the short term, this response seems to restore cardiovascular function to a normal homeostatic range but with time, sustained activation of these systems can lead to end-organ damage. One of the main characteristics of this response is the 
reactivation of the fetal gene programming that drives cells to de-differentiate. Thus, features of fetal heart metabolism re-emerge and include the preference of glucose metabolism over fatty acids as substrates for energy provision while early response genes such as c-myc and c-fos are highly expressed with isoform switches of many other proteins, including metabolic enzymes and sarcomeric proteins (decrease in $\alpha$ MHC expression and increase in $\beta$-MHC expression) $[1,4]$.

\section{Why Fetal Phenotype Is Reactivated ?}

The physiological relevance of the return of the heart to fetal gene programming remains still a debatable issue. There is a long held controversy and has been the source of many false starts and therapeutic strategies which have been abandoned over years (e.g., treatment with beta blockers once contraindicated and currently is cornerstone therapy). Heart failure physiologists view this as a maladaptive response which leads to the progressive decline in cardiac function. However, fetal reprogramming may also result in a "low-energy state" which adapts and protects the damaged myocardium upon stress [5]. In fact, the remodeled myocardium appears to be resistant to hypoxia or ischaemiareperfusion injury $[6,7]$.

\section{Return to Fetal Phenotype: An Opportunity for Regeneration: A Strong Hypothesis}

In our laboratory, studies on cardiomyocyte cell dedifferentiation/redifferentiation processes, has led us to the hypothesis that return to fetal phenotype and cell dedifferentiation may be a prerequisite permissive state for regeneration after stress. In fact, de-differentiated cells seem to have the ability to proliferate and/or grow and then to re-differentiate to specialized cells that comprise the regenerated structure or organ [8]. This mechanism appeared early in evolution and allowed living organisms to adapt to environmental stresses. Thus, it has long been recognized that salamanders have the ability to replace whole body parts or anurans can recover body parts at the embryonic stages through induction of cell dedifferentiation/redifferentiation processes [9]. Mammals retain the ability to regenerate but in a more restrictive form. Thus, neonatal mouse heart displays a regenerative potential early after birth in which differentiation is not complete [10]. This regenerative potential may be regained in adult life after stress-induced dedifferentiation and return to fetal phenotype. However, the ability of the cells to re-differentiate may be diminished upon intense and sustained stressful stimuli. This redifferentiation "deficit" may result in heart failure, cancer, and so forth [11], while interventions which potentially could enhance endogenous redifferentiation may restore tissue integrity and function (Figure 1).

\section{TH: a Regulator of Cell Dedifferentiation/Redifferentiation}

The molecular pathways which control cell dedifferentiation/redifferentiation process in response to stress are not fully understood. However, recent research points out an important physiological role of $\mathrm{TH}$ signaling in this process (Figure 1).

5.1. Evidence from Evolution. It is now recognized that important mechanisms that allowed living organisms to adapt to the environment and evolve, may be conserved in mammals and be of physiological and therapeutic relevance. Amphibian metamorphosis is one the natures' paradigms of tissue remodeling and regeneration and this process seems to be thyroid hormone dependent. Thus, almost 100 years ago, JF Gudernatsch made the remarkable discovery that equine thyroid extracts could accelerate the metamorphosis of tadpole into juvenile frogs [12]. Since then, several studies, if not all, have shown that the morphological and functional changes of metamorphosis are the result of alterations in the transcription of specific sets of genes induced by TH. Thyroid hormone system seems to be an ancestral hormone system and interestingly, thyroid hormone receptor (TR) gene is present at the base of biletarians before $\mathrm{TH}$ production, indicating an important physiological role of this receptor. Living organisms acquired the ability of producing $\mathrm{TH}$ with increasing evolutionary complexity [13].

The role of $\mathrm{TH}$ as developmental signal which can trigger the onset of amphibian metamorphosis has been documented in several studies with Xenopus laevis to be an ideal system for ascertaining the developmental roles of $\mathrm{TH}$ and its receptor [14]. Interestingly, this system reveals that regulation of $\mathrm{TH} / \mathrm{TR}$ axis allows the same simple molecule $\mathrm{TH}$ to induce completely opposite morphological responses in distinct tissues. In this context, the $\mathrm{TH}$ receptor alpha 1 (TR $\alpha 1)$ seems to play an important physiological role. This receptor appears to have a dual action which is dependent on its liganded or unliganded (with repressive action) state [15]. Thus, at the early developmental stages in which $\mathrm{TH}$ is low, TR $\alpha 1$ receptor is highly expressed and at its unliganded state acts as a repressor of TH-positive-regulated genes and prevents precocious metamorphosis [16]. At later stages, the rise in $\mathrm{TH}$ levels results in the conversion of the unliganded $\mathrm{TR} \alpha 1$ to the liganded state and triggers cell differentiation and completes metamorphosis [17].

The developmental changes of $\mathrm{TH}$ signaling seem to be of important physiological relevance for the response to stress. Thus, anurans can regenerate body parts after injury and this regenerative ability is higher when trauma occurs at early embryonic stages in which cell dedifferentiation prevails due the repressive actions of the unliganded TR $\alpha 1$. The regenerative potential is lost at later stages in which differentiation is progressed by the rise of TH. This response clearly shows that dedifferentiation may be a prerequisite for regeneration [14] (Figure 1).

5.2. Evidence from Cell Based and Animal Models. Based on the evidence obtained from the amphibian models of tissue remodeling, we investigated the potential role of TH signaling in a model of mammalian cardiac cell dedifferentiation/ redifferentiation induced by exposure of cardiomyocytes to stressful stimuli. Neonatal cardiomyocytes cultures were 


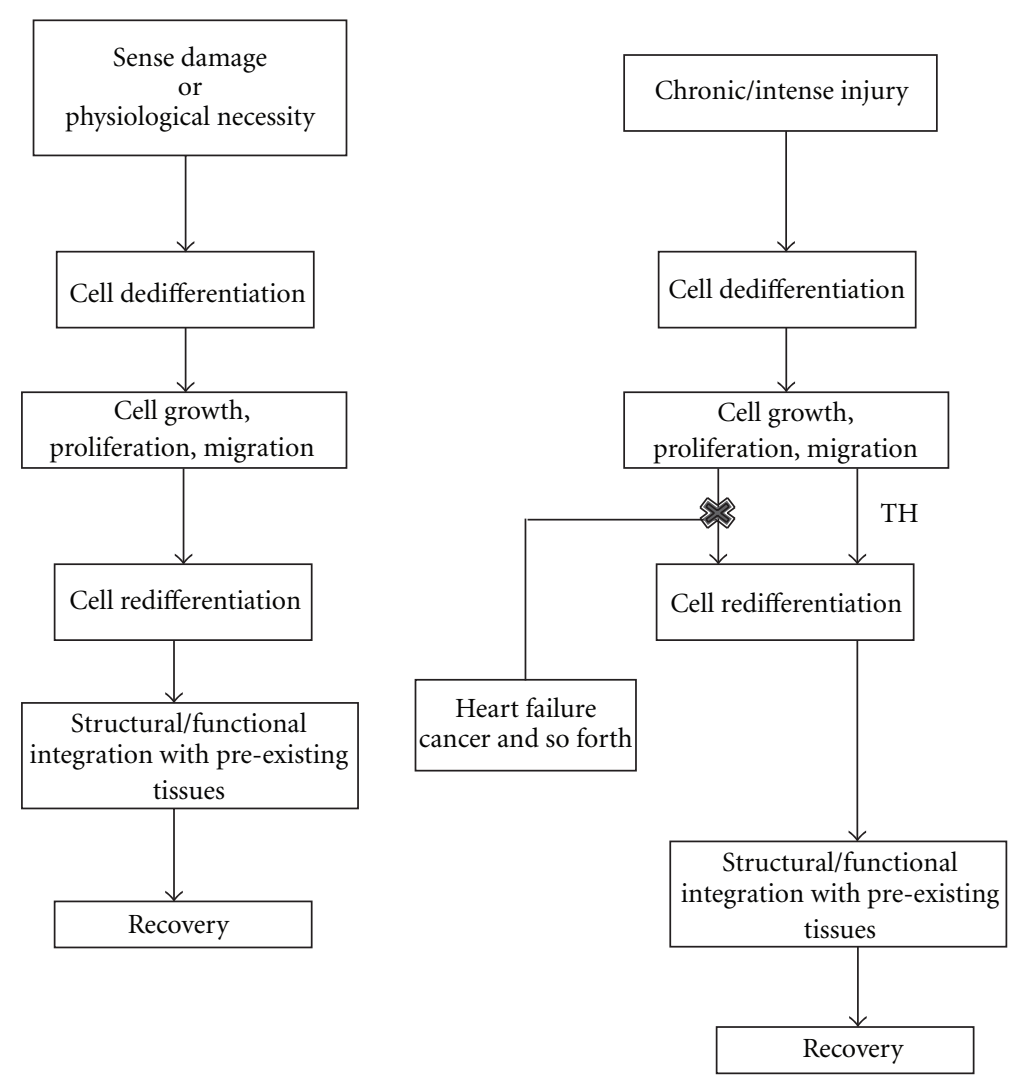

FIGURE 1: Schematic of the sequence of biological events occurring in response to environmental stimuli and lead to tissue restoration. In the case of intense and sustained stressful stimuli redifferentiation "deficit" occurs and results in a disease state (e.g., heart failure, cancer, etc.). Exogenous TH can enhance redifferentiation and restore damage.

exposed to phenylephrine (PE, an $\alpha 1$-adrenergic agonist) which is a progrowth stimulus and its effects are mediated by activation of intracellular growth kinases such as ERK and mTOR [18]. Thus, PE administration (in the absence of TH in the medium) resulted in marked cell dedifferentiation: PE treated cardiomyocytes, unlike the nontreated cardiomyocytes (which were almost of circular shape with poorly organized cytoskeleton), appeared to be large with disoriented, dense myofibrils, and undefined shape with filopodia-like structures [19]. Myosin isoform expression switched to a fetal pattern with a marked increase in $\beta$-MHC expression. This response was associated with a redistribution of TR $\alpha 1$ with increased content of TR $\alpha 1$ in the nucleus and decreased in the cytosol and was abolished by inhibition of activation of ERK signaling with PD98059 [19]. Furthermore, an intact mTOR signaling pathway was found to be required for this response. In fact, inhibition of mTOR signaling with rapamycin not only abolished PEinduced nuclear TR $\alpha 1$ overexpression but resulted in marked TR $\alpha 1$ decrease with cell atrophy [20] (Figure 2). These data clearly show that stress-induced TR $\alpha 1$ overexpression may be a potential mechanism of cardiomyocyte dedifferentiation. Transfection and pharmacological cell-based studies and studies in animals provide further support to this notion. Thus, overexpression of unliganded TR $\alpha 1$ in neonatal cardiomyocytes resulted in cell growth with fetal pattern of myosin isoform expression [21], and cardiomyocytes from mice with dominant negative TR $\alpha 1$ displayed impaired calcium handling and contraction [22]. Similarly, pharmacological inhibition of T3 binding to TR $\alpha 1$ prevented cardiac embryonic cells differentiation [19]. In accordance to this evidence, TR $\alpha 1$ overexpression was shown to occur during the development of pathological hypertrophy after myocardial infarction in rats and decline with the progression to heart failure [20]. Further support to the role of TR $\alpha 1$ as a critical regulator of cell dedifferentiation/redifferentiation in response to stress was provided by the effects of addition of TH in the medium of cells stressed by PE. Thus, as in anurans, we raised the levels of T3 in the medium to convert the unliganded TR $\alpha 1$ to a liganded receptor. Interestingly, this resulted in cell redifferentiation as this was evident by the switch of fetal-like pattern of MHC expression to the adult pattern and changes in cell morphology: cells displayed an elongated shape, with a filamentous actin pattern organized into orderly arrays [19] (Figure 2).

\section{TH Promotes Endogenous Regeneration of the Damaged Heart}

On the basis of the evidence obtained from cell and animal models it seems likely that treatments targeting the $\mathrm{TH}$ 


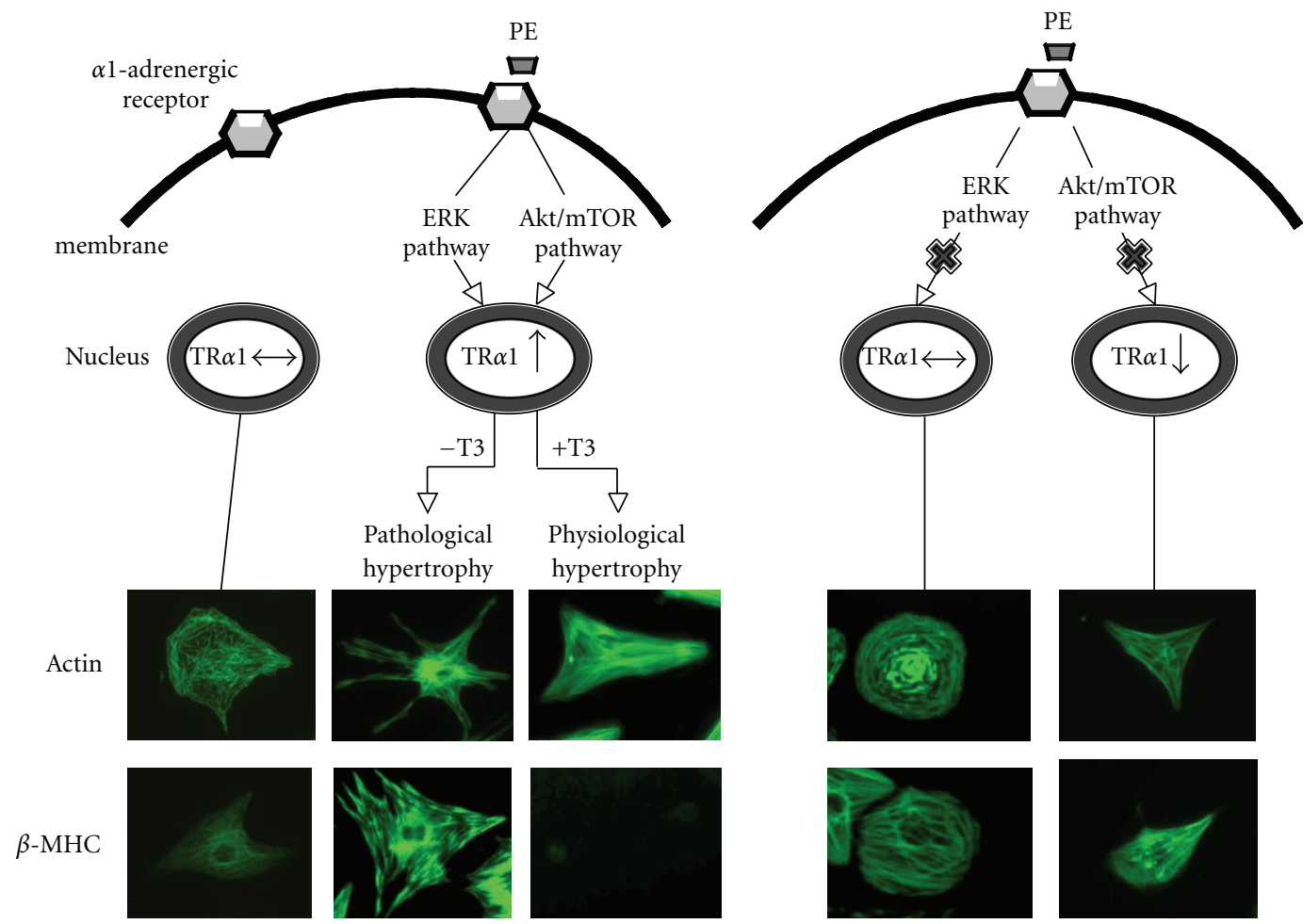

FIGURE 2: Cardiac cells are de-differentiated upon exposure to progrowth stimuli such as phenylephrine (PE). This response is mediated via ERK/TR $\alpha 1$ and requires an intact mTOR signaling. Inhibition of mTOR signaling with rapamycin not only abolishes PE-induced nuclear TR $\alpha 1$ overexpression but results in marked TR $\alpha 1$ decrease with cell atrophy. De-differentiated cells retain the ability to redifferentiate when T3 is added to the medium. TR $\alpha 1$ by its dual action (liganded versus unliganded) seems to act as a regulator of the cell dedifferentiation/redifferentiation process.

signaling may promote endogenous regeneration of the damaged myocardium [23]. Several lines of experimental evidence support this notion [24-29] (Figure 3). Thus, $\mathrm{TH}$ treatment early after infarction resulted in marked improvement of contractile indices independent of loading conditions, such as $+\mathrm{dp} / \mathrm{dt}$ and $-\mathrm{dp} / \mathrm{dt}$, due to favorable cell remodeling as indicated by the switch of MHC isoform expression from the fetal to adult pattern [26]. Furthermore, TH increased cardiac mass and normalized wall stress while it preserved left ventricular geometry to the ellipsoidal shape. These important structural and functional changes were translated to enhanced myocardial performance as indicated by significant improvement of left ventricular ejection fraction [27]. Similar effects were evident even after the development of pathological hypertrophy in old myocardial infarction. In fact, TH was shown to have the ability to convert pathological to physiological hypertrophy [30] (Figure 3).

\section{TH and Cell Differentiation: Potential Underlying Mechanisms}

Cell differentiation seems to be a redox regulated process. This mechanism has been demonstrated in cultures of glial oligodendrocyte/astrocyte progenitor cells in which the more oxidizing cytoplasmic environment induced by growth factors such as thyroid hormone and bone morphogenic protein 4 and the chemical oxidant tert-butyl hydroperoxide favored cell oligodendrocyte formation. By contrast, a more reducing cytoplasmic environment induced by growth in the presence of a basic fibroblast growth factor, plateletderived growth factor, or their combination favored the maintenance of the progenitor cells [31]. Similarly, the induction of cardiac hypertrophy by TH is shown to involve redox regulated signaling pathways [32]. Furthermore, TH can alter cardiac cell shape and growth via activation of distinct growth kinase signaling pathways. Thus, TH involves ERK signaling to change cell shape and geometry whereas cell growth is an mTOR-dependent process [33].

\section{The TH "Paradox"}

It is now recognized that cell differentiation and cell survival may share common signaling pathways. Thus, the THinduced activation of redox-regulated signaling pathways which mediate cell differentiation, results also in the upregulation of redox-regulated cardioprotective molecules, such as heat shock proteins which can increase tolerance of the cell against ischaemia [34, 35]. Furthermore, TR $\alpha 1$ receptor which is critical in cell differentiation appears also to mediate $\mathrm{TH}$-induced cardioprotection (unpublished data). These data provide an explanation regarding the paradox 

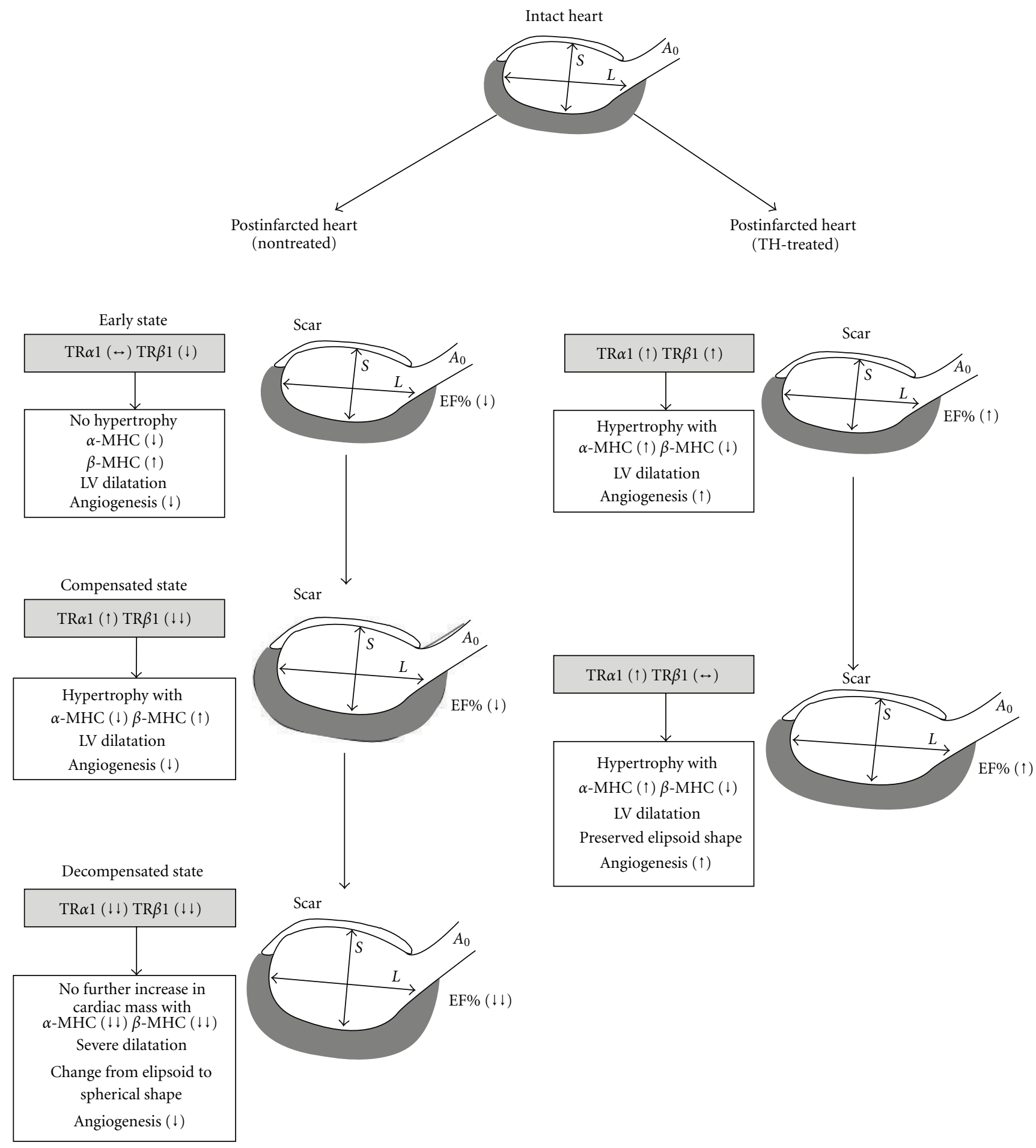

(a)

(b)

FIGURE 3: Schematic of molecular, structural, and functional changes during post-ischaemic cardiac remodeling in untreated (a) and THtreated hearts (b). TH shortly after myocardial infarction induces favorable changes in left ventricular chamber remodeling in a timedependent manner; TH treatment accelerates the development of cardiac hypertrophy which normalizes wall tension and reshapes left ventricular chamber towards a more ellipsoidal shape at later stages [20]. 
of $\mathrm{TH}$ being rather protective than detrimental for the ischaemic heart although it increases oxygen consumption (by accelerating heart rhythm and increasing cardiac contractility) and depletes the heart from glycogen [36]. Here, it should be noted that the protective effect of $\mathrm{TH}$ has also been observed in models of neuronal injury [37].

\section{Does TH Availability for a Diseased Human Myocardium Represent a Critical Point?}

As clearly documented by several experimental animal data, most of the effects of $\mathrm{TH}$ on cardiac function are mediated by binding of biologically active T3 to nuclear TR. Thus, T3 tissue concentration represents the switching factor in $\mathrm{TH}$ signalling. Not surprisingly, in patients with primary thyroid mild dysfunction, cardiovascular adverse manifestations have widely been described [38, 39]. An altered TH bioavailability has also been documented in cardiac patients without primary thyroid disorders. The most frequent change in $\mathrm{TH}$ metabolism in patients with severe cardiac disease including heart failure, myocardial infarction, and coronary artery bypass is a significant fall in circulating biologically active T3 and a corresponding increase in reverse T3 (rT3), the inactive T3 metabolite[40, 41]. The low-T3 syndrome occurs in approximately 20$30 \%$ of patients with heart failure [42-44] with significantly higher incidence in patients with NYHA functional class IIIIV than in those with NYHA I-II $[43,45]$. The occurrence of a low T3 syndrome, however, does not represent a peculiar pattern of cardiac disease because it has been documented in several noncardiac illnesses. The underlying pathophysiological mechanisms are the reduced enzyme activity of $5^{\prime}$ monodeiodinase responsible for converting T4 into T3 and the increased enzyme activity of 5 monodeiodinase responsible for converting $\mathrm{T} 4$ into the inactive $\mathrm{r}-\mathrm{T} 3$ in peripheral tissues [46].

Regardless of the cause, type (i.e., acute or chronic), severity, and time course of the disease, the first and dominant pathophysiological hypothesis on the meaning of low-T3 syndrome was that decreased T3 concentrations are merely the result of an adaptive process finalized to reduce energy expenditure and thus, having beneficial effects through the reduction in metabolic demand [47]. However, experimental and clinical evidence challenged this interpretation. In an ex vivo study on human myocardial biopsies, we demonstrated that long-term T3 deprivation negatively affected both overall tissue architecture of cultured myocardial slices and calcium handling of the outgrowing cardiomyocytes [48] (Figure 4), indicating that a low-T3 state, as observed during evolution of cardiac disease, can be considered a true hypothyroid-like cardiac condition that worsens per se cardiomyocyte remodeling and dysfunction. In line with the above interpretation, clinical observational studies have shown the important negative prognostic impact of lowT3 syndrome in patients after acute myocardial infarction and cardiopulmonary bypass and during evolution of heart failure $[49,50]$. A negative correlation was also found between plasma FT3 concentrations and the extent of myocardial damage after AMI [51].

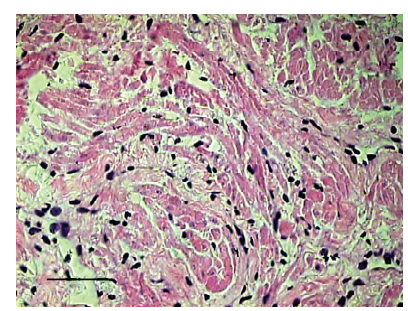

(a)

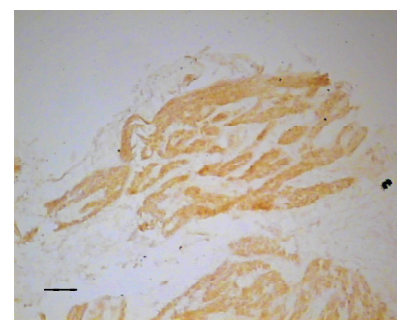

(c)

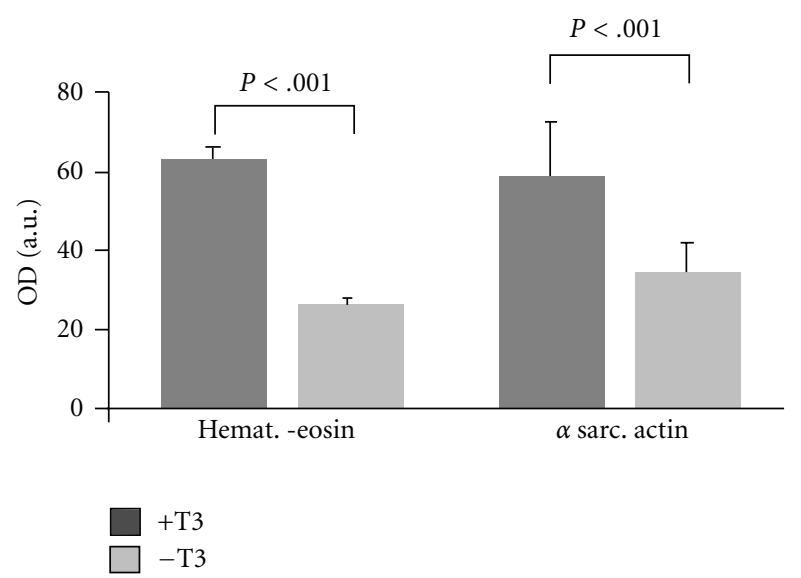

(e)

Figure 4: Structural and phenotypic effects of T3 supplementation. After 10 days of culture, T3-supplemented myocardial fragments presented better preserved cardiomyocytes both at histological (a) and immunohistochemical examination (c). Weaker staining and progressive atrophy was observed in the corresponding untreated samples ((b) and (d), resp.). Myocardial sections were stained hematoxylin eosin (a), (b) for total protein content evaluation or immunostained for $\alpha$-sarcomeric actinin (c), (d) for sarcomeric specif protein content. Images were acquired with a CCD camera and optical density was measured (scale bar $=50 \mu \mathrm{m}$ ). (e) Quantification of the histological results obtained from hematoxylineosin and $\alpha$-sarcomeric-actinin staining of 10-day-old human myocardium in culture. $P$ was determined using the two-tailed unpaired Student's $t$-test; data are expressed as mean \pm SEM (experimental data derived from [28]).

Independently of the parameter used (i.e., a reduction in circulating levels of $\mathrm{T} 3$, an increase in inactive $\mathrm{rT} 3$, a low free $\mathrm{T} 3$ index/rT3 ratio, and an free T3/free T4 ratio), previous works showed that an altered peripheral TH pathway was in any case associated with high incidence of fatal events consisting of cardiac or cumulative death, or heart transplantation $[42,43,52]$. In a study from our laboratory 
the probability of death, either cardiac or cumulative, was significantly higher in patients with than without low-T3 syndrome [53]. In another study that enrolled 281 inpatients with ischemic and nonischemic heart [45], we found that total T3 and left ventricular ejection fraction were the only independent predictive variables at multivariate analysis of both cardiac and cumulative death. More recently, these results have been confirmed in a larger cohort of patients with low-T3 syndrome being the cardiac and overall deaths, respectively, 3.4\% and 7.3\% in euthyroidism, and $6.5 \%$ and $13.1 \%$ in low-T3 syndrome patients [54].

\section{TH Therapy in Patients with Heart Disease}

10.1. General Considerations. Besides experimental findings on animal studies, several lines of evidence suggest that some components of the TH signaling could be impaired also in dysfunctioning human heart.

Important acquisitions of knowledge have been derived from a pioneering experiment in a patient with severe hypothyroidism and heart failure in whom several myocardial biopsies were taken; during hypothyroidism MHC alpha mRNA was markedly lower with the opposite for MHC beta. Also phospholamban was 10-fold higher in the hypothyroid heart when compared with euthyroid heart. With restoration of euthyroidism all changes reverted to normal and a normal cardiac function was restored [55]. These direct in vivo human observations are the basis of the afterwards so-called activation of a fetal gene program otherwise indicated as "recapitulation of the fetal phenotype" [56, 57] secondary to the hypothyroid state, all contributing to the decreased contractile function typical of adult HF and a reversal of genotype/phenotype to a more fetal-like cardiac state.

Notably, in a therapeutic perspective, the activation of the fetal gene program observed during evolution of heart failure in adult life appears to be potentially reversible when the TH profile is normalized. The restoration of a physiological TH/TR interaction might counteract progression of heart disease by different mechanisms including: (1) a positive remodelling through the modulation of myocardial gene expression; (2) an improvement in cardiac systolic and diastolic function with a consequent improvement in haemodynamics; (3) an improvement in myocardial perfusion. Last but not least, a positive effect on quality of life by combining multisystems actions of the TH. Actually the rationale for systemic administration of $\mathrm{TH}$ is based on the additional systemic actions of THs, in particular on skeletal muscle, kidney, and brain that could be important components of the progression from organ-limited to wholebody disease.

10.2. TH-Based Therapy in Cardiac Patients: From Fear to Hope. Treatment with $\mathrm{TH}$ represents a challenging field in cardiac patients with an altered TH metabolism. The potential of novel $\mathrm{TH}$ therapies that address the molecular biology of thyroid dysfunction and heart disease represents thus an attractive area of multidisciplinary interest. Based on the available experimental evidence the final goal of
TH-based treatment should be to restore and maintain over time a physiological thyroid state when an altered $\mathrm{TH}$ metabolism and action does occur as in postischemic remodeling. On the other hand, in normal, nonischaemic heart, excessive TH may produce several cardiovascular deleterious manifestations including increased heart rate, susceptibility to atrial and ventricular arrhythmias, increased oxygen demand, and cardiac hypertrophy both in humans and animals $[58,59]$. Subjects with long-term TH excess may also develop cardiac hypertrophy caused by both direct effects of TH on functional contractile and structural protein synthesis as well as indirectly by increasing cardiac load [60]. In addition, long-term L-T4 treatment has been shown to produce significant left ventricular hypertrophy and increase in left ventricular mass index [61]. TH excess has been also implicated as primary cause of impaired cardiopulmonary exercise tolerance probably due to a reduction in cardiac functional reserve [60]. The mechanisms of transition from cardiac hypertrophy to heart failure, however, still remain largely unclear [59]. An increase in LV mass has also been reported in long-term thyroid hyperactivity and could counteract the beneficial effect of TH on diastolic performance by worsening diastolic ventricular filling and systolic performance on effort [62]. Moreover, long-term $\mathrm{TH}$ overload may enhance the sensitivity of myocardium to catecholamines and increase the activity of renin-angiotensin system in myocardium [63]. Consequently, chronically elevated catecholamines and/or angiotensin II in myocardium may reduce cardiac contractility and promote apoptosis of cardiomyocytes in humans and animals [64]. By these premises, it is not surprising that some patients with endogenous or exogenous subclinical hyperthyroidism may show significant changes in echocardiographic parameters associated with systolic and diastolic dysfunction, both potentially contributing to increased cardiovascular risk $[65,66]$. The small number of patients and the lack of control [65] of the above studies may limit, however, the clinical relevance of data. Observational, large-scale studies on relationships between cardiovascular morbidity and mortality in exogenous subclinical hyperthyroidism induced by long-term LT4 treatment have yielded, however, conflicting results [67] and only in patients with endogenous subclinical hyperthyroidism an increased risk of nonfatal morbidity and dysrhythmia has been reported [68]. An increased cardiovascular and cerebrovascular mortality has also been described in a community-based review of subjects with subclinical hyperthyroidism followed over a 10 -year period [69]; the role of dysrhythmias may be critical in accounting for some of the excess cardiovascular and cerebrovascular mortality observed in those patients [70].

The emerging clinical and experimental knowledge, taken as a whole, suggests that TH treatment may provide more beneficial than harmful effects including reversal and/or limitation of remodeling, and progression to cardiac dysfunction. However, despite indications on positive actions of restoring a physiologic TH signalling in a damaged heart, interventional trials by the use of THs or THs analogs have been largely discouraged in cardiac patients. Common belief of physicians is that exogenous TH (or TH analogue) 
therapy represents in any case an injudicious and dangerous approach with risk of arrhythmia, myocardial ischemia/ infarction, and worsening of congestive heart failure. The origin of this belief is, however, largely debatable and mostly based on results from the Coronary Drug Project (CDP) study [71].

CDP demonstrated adverse outcomes, particularly in regards to the proarrhythmic effects of Dextro (D)-T4 [71].The D-T4 preparation (Choloxin, Flint Laboratories) used in the CDP was contaminated with a high level of active L-T4 [72]. Therefore, the cumulative dose of administered L-T4 was toxic, being equivalent to several times the L-T4 dose that would be given to a patient to correct hypothyroidism. For this reason, the CDP did not provide helpful information regarding the therapeutic use of physiological $\mathrm{TH}$ in the treatment of cardiac patients. To our knowledge, all pilot interventional studies with the use of synthetic TH conducted in cardiac disease have suggested, on the contrary, its safety $[50,73]$ and provided some evidence for beneficial effects, mainly in patients undergoing cardiac surgery as well as in those with heart failure with or without cardiogenic shock [50, 73-77]. Type, dosage, and timing of TH-based treatment still remain, however, important open issues which are awaited to be addressed in clinical trials.

10.3. TH-Based Therapeutic Strategies in Cardiac Patients. From a theoretical point of view, therapeutic strategies that can be employed to optimize $\mathrm{TH}$ signalling in the presence of $\mathrm{HF}$ can be summed up in the following five points: (1) administration of synthetic L-T4; using this approach the main physiological pathway of secretion and peripheral metabolism of TH system is preserved; (2) administration of synthetic L-T3: by this way the physiological pattern of peripheral conversion from T4 into T3, which is impaired in presence of a low-T3 syndrome, is bypassed through direct application of the biologically active TH; (3) administration of a TH analogue, that is of a synthetic and, as much possible, cardiotropic compound showing similar positive effects than the natural TH but lower adverse effects; (4) genetic manipulation of the expression of cardiovascular deiodinases: in this case the main goal is to increase local production and bioavailability of T3; (5) genetic manipulation of the cardiovascular TR pattern: in this case the goal is to increase hormonal signalling at the receptor level while preserving T3 availability. At present, the first three approaches have been applied in a few human studies, and with a low number of patients [78-80] whereas the remaining therapeutic options are still in the experimental animal stage $[81,82]$.

10.4. L-T4 Administration. Moruzzi et al. published two studies in which synthetic L-T4 was given orally at the "physiological" dose of $0.1 \mathrm{mg}$ per day and cardiovascular effects were assessed after short-term (one-week) treatment and after continuous three-month treatment [79, 83]. In particular, the latter is the only published study that tried to assess the long-term effects of $\mathrm{TH}$ in a model of randomised placebo versus L-T4 therapy study. In both studies L-T4 was well tolerated and induced significant improvement in cardiac pump function, consisting of enhanced resting LVEF, resting cardiac output, and functional capacity during exercise.

10.5. L-T3 Administration. In the pioneer study by Hamilton et al. a protocol based on administration of intravenous bolus dose followed or not by a few hours of L-T3 infusion in patients with advanced HF and low T3 levels and/or elevated rT3 concentrations was adopted [78] However, the study's main weakness was the wide variability in scheduled time and dose of the administered L-T3 (cumulative dose from 0.15 to $2.7 \mu \mathrm{g} / \mathrm{kg}$ with infusion time ranging from a minimum of 6 to a maximum of $12 \mathrm{~h}$ ) in a small, nonrandomized patient population. Although circulating T3 obtained after L-T3 administration was widely variable and in all cases clearly above the upper limit of normal range, no side effects (i.e., no myocardial ischemia or complex arrhythmias) have been documented. In particular, in patients who received the largest doses of L-T3, cardiac output improved significantly starting from $2 \mathrm{~h}$ after administration with a parallel decrease in systemic vascular resistance. Importantly, heart rate did not change nor did metabolic demand as assessed by indirect calorimetry. Nevertheless, the administration of LT3 at high doses, mimicking a hyperthyroid status, may be detrimental when used for long term. In fact, experimental data clearly documented that high doses of L-T3 were able to induce myocardial hypertrophy, and that they were only initially associated with an improved cardiac performance, but followed by a decline after 1 month of treatment [84]. This finding was also associated with increased expression of uncoupling proteins (UCP2 and UCP3) which may be responsible for the decrease in mitochondrial efficiency during thyroid hyperfunction [85].

In a pilot study from our laboratory L-T3 was administered at a "physiological" dose of $20 \mu \mathrm{g} / \mathrm{day} / \mathrm{m}^{2}$ body surface for a period of $96 \mathrm{~h}$ in six patients with advanced heart failure and low-T3 syndrome who were undergoing stable conventional treatment and salt intake. L-T3 constant infusion induced a progressive reduction in systemic vascular resistance and an increase in left ventricular ejection fraction and cardiac output, the latter invasively monitored by SwanGanz catheter; urinary output also improved, whereas no changes in heart rate and systemic arterial BP were observed [78-80]. An improvement in overall cardiac performance as documented by an increased stroke volume and left ventricular end-diastolic diameter, all noninvasively assessed by cardiac magnetic resonance imaging, was also documented after 3-day L-T3 substitutive infusion in a placebo-controlled study on patients with chronic and clinically stable dilated cardiomyopathy and low-T3 syndrome. Importantly, the improvement in cardiac performance was not associated with an increase in myocardial $\mathrm{O} 2$ consumption, nor there was an increase in total cardiac work. Also the concomitant evidence for a neuroendocrine deactivation, probably contributing to the improved hemodynamic conditions, as documented by the decrease in noradrenaline circulating plasma levels and of the counterpart NT-proBNP secondary to L-T3 treatment in patients with heart failure needs further exploration in future studies. In conclusion, overall the above 
observations suggest that the modality of the therapeutic approach is likely the key point when testing TH treatment in cardiac patients with nonthyroidal illness.

10.6. Thyroid Hormone Analogues Administration. In 1992, a TH analogue (DITPA) showed cardiac inotropic selectivity comparable to $\mathrm{TH}$ itself, accompanied by minimal effects on heart rate and metabolic activity [86]. Long-term administration of DITPA seems also to stimulate coronary arteriolar growth without inducing cardiac hypertrophy, by upregulating key angiogenic growth factors [87]. The rationale of using DITPA was to avoid the detrimental effects of exogenously administered $\mathrm{TH}$, such as an increase in heart rate and body metabolism (3). While the rationale appears logical, the results in human studies do not appear so favourable. In a pilot randomized DITPA versus placebo clinical study, DITPA was administered in patients with NYHA functional class II-III for 2-4 weeks at a dosage of $1.87-3.75 \mu \mathrm{g} / \mathrm{Kg}$ body weight per day. The major hemodynamic effects consisted in improved cardiac index and decreased systemic vascular resistance index. Further, diastolic function was ameliorated as documented by the decrease in the isovolumetric relaxation time which is a parameter of diastolic cardiac relaxation properties [88].

In a very recent placebo-controlled study by Goldman et al. [89]. The TH analogue 3,5 diiodothyropropionic acid (DITPA) was administered in patients with congestive heart failure. DITPA induced an increase in both cardiac index and heart rate associated with a reduction in systemic vascular resistance. However, no improvement on outcome or symptoms was observed, but rather fatigue was more frequent in the DITPA Group. Importantly, weight loss, increased heart rate, fatigue, reduction in serum cholesterol, and suppressed TSH, all well-known signs and symptoms of thyrotoxicosis, suggest an excess of TH action induced by DITPA at the doses utilized in that study [90].

10.7. Genetic Manipulation. Emerging experimental data encourage the adoption of a new target-organ strategy based on genetic manipulation. In this way it is somewhat possible to overcome all the limitations related to a systemic administration of synthetic native hormone or TH analogues. In the rat model of pressure overload induced cardiac dysfunction, the enhancement of T3 signalling by increased deiodinase Type 2 activity or TR expression has been linked to improve cardiac contractile function and prevention of $\operatorname{HF}[81,82]$. In particular, the mechanism for preventing HF may depend on avoiding the reversion from an adult to a fetal genelike state, that is, the shift from $\alpha-\mathrm{MCH}$ to $\beta-\mathrm{MCH}$ and decreased SERCA2, which has also been demonstrated in the human failing heart in response to hypothyroidism. Moreover, discovery in human VSM cells and in animal microcirculatory system of a deiodinating pathway able to produce local T3 with vasodilating action $[91,92]$ confirms that the vascular system is also a direct target of TH and may be a potential point of genetic manipulation to modulate vascular peripheral resistance during evolution of HF.

\section{Conclusions}

Overall available data on patients with cardiac patients treated with synthetic THs suggest that most of the observed effects on cardiac performance can be explained on the basis of both genomic and nongenomic $\mathrm{TH}$ direct actions on cardiac and vascular systems, perfectly in line with our knowledge on cellular mechanisms induced by $\mathrm{TH}$.

On the basis of the above-mentioned experimental and clinical findings, in 2009 we started a phase II, randomized, double blind, placebo-controlled study by the use of substitutive doses of synthetic L-triiodothyronine in patients with STEMI (ST-Elevation Myocardial Infarction) and borderline/reduced circulating T3 [93]. Treatment with synthetic TH or placebo starts during the in hospital period in presence of stable haemodynamic conditions (i.e., 48$72 \mathrm{hrs}$ after STEMI) and will be taken for further 6 months after hospital discharge (Chronic phase). Actually, while inhospital mortality from acute MI has declined in recent years due to improved early intervention, the five-year rate of heart failure has increased in these patient [94]. Furthermore, severe diastolic dysfunction is a strong predictor of oneyear rehospitalisation in MI survivors [95]. It is thus likely that TH treatment will specifically target chamber dilatation and diastolic dysfunction by its beneficial effects on cardiac perfusion, architecture and function. Primary objectives of the study are to investigate:

(1) the safety and feasibility of synthetic TH replacement in patients with STEMI;

(2) TH replacement therapy effects on postischemic remodelling and LV function;

(3) the effects of $\mathrm{TH}$ replacement therapy on clinical outcome in terms of major (cardiac and non cardiac death, reinfarction) and minor (recurrence of angina, coronary revascularization, and hospital readmission) events.

Secondary objectives of the study are to evaluate the effects of thyroid hormone therapy on

(1) infarct size, regional wall motion abnormalities, systolic, and diastolic myocardial function;

(2) neuroendocrine imbalance;

(3) patients functional capacity, quality of life, cognitive and behavioural status.

When available, data from the above study will help to clarify the potential clinical usefulness of TH treatment as a novel strategy to protect a damaged myocardium from pathological growth and remodelling after an acute ischemic insult.

\section{Acknowledgment}

The study was partly funded by ongoing European Community ITC-STREP FP7 PONTE Research Project (Project no. 247945) Efficient Patient Recruitment for Innovative Clinical Trials of Existing Drugs to Other Indications. 


\section{References}

[1] H. Taegtmeyer, S. Sen, and D. Vela, "Return to the fetal gene program: a suggested metabolic link to gene expression in the heart," Annals of the New York Academy of Sciences, vol. 1188, pp. 191-198, 2010.

[2] C. Pantos, I. Mourouzis, and D. V. Cokkinos, "New insights into the role of thyroid hormone in cardiac remodeling: time to reconsider?" Heart Failure Reviews, vol. 16, no. 1, pp. 79-96, 2011.

[3] Y.-K. Lee, K.-M. Ng, Y.-C. Chan et al., "Triiodothyronine promotes cardiac differentiation and maturation of embryonic stem cells via the classical genomic pathway," Molecular Endocrinology, vol. 24, no. 9, pp. 1728-1736, 2010.

[4] B. Swynghedauw, "Molecular mechanisms of myocardial remodeling," Physiological Reviews, vol. 79, no. 1, pp. 215-262, 1999.

[5] M. Rajabi, C. Kassiotis, P. Razeghi, and H. Taegtmeyer, "Return to the fetal gene program protects the stressed heart: a strong hypothesis," Heart Failure Reviews, vol. 12, no. 3-4, pp. 331-343, 2007.

[6] C. Pantos, I. Mourouzis, A. Dimopoulos et al., "Enhanced tolerance of the rat myocardium to ischemia and reperfusion injury earlyafter acute myocardial infarction," Basic Research in Cardiology, vol. 102, no. 4, pp. 327-333, 2007.

[7] C. Pantos, I. Mourouzis, T. Saranteas et al., "Thyroid hormone receptors $\alpha 1$ and $\beta 1$ are downregulated in the post-infarcted rat heart: consequences on the response to ischaemiareperfusion," Basic Research in Cardiology, vol. 100, no. 5, pp. 422-432, 2005.

[8] S. J. Odelberg, "Inducing cellular dedifferentiation: a potential method for enhancing endogenous regeneration in mammals," Seminars in Cell and Developmental Biology, vol. 13, no. 5, pp. 335-343, 2002.

[9] A. Sánchez Alvarado, "Regeneration in the metazoans: why does it happen?” BioEssays, vol. 22, no. 6, pp. 578-590, 2000.

[10] E. R. Porrello, A. I. Mahmoud, E. Simpson et al., "Transient regenerative potential of the neonatal mouse heart," Science, vol. 331, no. 6020, pp. 1078-1080, 2011.

[11] N. J. Oviedo and W. S. Beane, "Regeneration: the origin of cancer or a possible cure?" Seminars in Cell and Developmental Biology, vol. 20, no. 5, pp. 557-564, 2009.

[12] J. F. Gudernatsch, "Feeding experiments on tadpoles-I: the influence of specific organs given as food on growth and differentiation. A contribution to the knowledge of organs with internal secretion," Development Genes and Evolution, vol. 35, no. 3, pp. 457-483, 1912.

[13] M. Paris, F. Brunet, G. V. Markov, M. Schubert, and V. Laudet, "The amphioxus genome enlightens the evolution of the thyroid hormone signaling pathway," Development Genes and Evolution, vol. 218, no. 11-12, pp. 667-680, 2008.

[14] J. M. W. Slack, G. Lin, and Y. Chen, "Molecular and cellular basis of regeneration and tissue repair: the Xenopus tadpole: a new model for regeneration research," Cellular and Molecular Life Sciences, vol. 65, no. 1, pp. 54-63, 2008.

[15] O. Chassande, "Do unliganded thyroid hormone receptors have physiological functions?" Journal of Molecular Endocrinology, vol. 31, no. 1, pp. 9-20, 2003.

[16] Y. Sato, D. R. Buchholz, B. D. Paul, and Y. B. Shi, "A role of unliganded thyroid hormone receptor in postembryonic development in Xenopus laevis," Mechanisms of Development, vol. 124, no. 6, pp. 476-488, 2007.

[17] J. D. Furlow and E. S. Neff, "A developmental switch induced by thyroid hormone: Xenopus laevis metamorphosis," Trends in Endocrinology and Metabolism, vol. 17, no. 2, pp. 40-47, 2006.

[18] M. Rolfe, L. E. McLeod, P. F. Pratt, and C. G. Proud, "Activation of protein synthesis in cardiomyocytes by the hypertrophic agent phenylephrine requires the activation of ERK and involves phosphorylation of tuberous sclerosis complex 2 (TSC2)," Biochemical Journal, vol. 388, no. 3, pp. 973-984, 2005.

[19] C. Pantos, C. Xinaris, I. Mourouzis et al., "Thyroid hormone receptor $\alpha 1$ : a switch to cardiac cell "metamorphosis"?" Journal of Physiology and Pharmacology, vol. 59, no. 2, pp. 253269, 2008

[20] C. Pantos, I. Mourouzis, G. Galanopoulos et al., "Thyroid hormone receptor 1 downregulation in postischemic heart failure progression: the potential role of tissue hypothyroidism," Hormone and Metabolic Research, vol. 42, no. 10, pp. 718-724, 2010.

[21] K. Kinugawa, M. Y. Jeong, M. R. Bristow, and C. S. Long, "Thyroid hormone induces cardiac myocyte hypertrophy in a thyroid hormone receptor $\alpha 1$-specific manner that requires TAK1 and p38 mitogen-activated protein kinase," Molecular Endocrinology, vol. 19, no. 6, pp. 1618-1628, 2005.

[22] P. Tavi, M. Sjögren, P. K. Lunde et al., "Impaired $\mathrm{Ca}^{2+}$ handling and contraction in cardiomyocytes from mice with a dominant negative thyroid hormone receptor $\alpha$, Journal of Molecular and Cellular Cardiology, vol. 38, no. 4, pp. 655-663, 2005.

[23] C. Pantos, I. Mourouzis, and D. V. Cokkinos, "Thyroid hormone as a therapeutic option for treating ischaemic heart disease: from early reperfusion to late remodelling," Vascular Pharmacology, vol. 52, no. 3-4, pp. 157-165, 2010.

[24] K. K. Henderson, S. Danzi, J. T. Paul, G. Leya, I. Klein, and A. M. Samarel, "Physiological replacement of $\mathrm{T}_{3}$ improves left ventricular function in an animal model of myocardial infarction-induced congestive heart failure," Circulation: Heart Failure, vol. 2, no. 3, pp. 243-252, 2009.

[25] Y. F. Chen, S. Kobayashi, J. Chen et al., "Short term triiodoL-thyronine treatment inhibits cardiac myocyte apoptosis in border area after myocardial infarction in rats," Journal of Molecular and Cellular Cardiology, vol. 44, no. 1, pp. 180-187, 2008.

[26] C. Pantos, I. Mourouzis, K. Markakis et al., "Thyroid hormone attenuates cardiac remodeling and improves hemodynamics early after acute myocardial infarction in rats," European Journal of Cardio-thoracic Surgery, vol. 32, no. 2, pp. 333-339, 2007.

[27] C. Pantos, I. Mourouzis, K. Markakis, N. Tsagoulis, M. Panagiotou, and D. V. Cokkinos, "Long-term thyroid hormone administration reshapes left ventricular chamber and improves cardiac function after myocardial infarction in rats," Basic Research in Cardiology, vol. 103, no. 4, pp. 308-318, 2008.

[28] F. Forini, V. Lionetti, H. Ardehali et al., "Early long-term LT3 replacement rescues mitochondria and prevents ischemic cardiac remodelling in rats," Journal of Cellular and Molecular Medicine, vol. 15, no. 3, pp. 514-524, 2011.

[29] C. Kalofoutis, I. Mourouzis, G. Galanopoulos et al., "Thyroid hormone can favorably remodel the diabetic myocardium after acute myocardial infarction," Molecular and Cellular Biochemistry, vol. 345, no. 1-2, pp. 161-169, 2010.

[30] C. Pantos, I. Mourouzis, N. Tsagoulis et al., "Thyroid hormone at supra-physiological dose optimizes cardiac geometry and improves cardiac function in rats with old myocardial infarction," Journal of Physiology and Pharmacology, vol. 60, no. 3, pp. 49-56, 2009. 
[31] A. W. Linnane and H. Eastwood, "Cellular redox regulation and prooxidant signaling systems: a new perspective on the free radical theory of aging," Annals of the New York Academy of Sciences, vol. 1067, no. 1, pp. 47-55, 2006.

[32] A. S. R. Araujo, P. Schenkel, A. T. Enzveiler et al., "The role of redox signaling in cardiac hypertrophy induced by experimental hyperthyroidism," Journal of Molecular Endocrinology, vol. 41, no. 5-6, pp. 423-430, 2008.

[33] C. Pantos, Ch. Xinaris, I. Mourouzis, V. Malliopoulou, E. Kardami, and D. V. Cokkinos, "Thyroid hormone changes cardiomyocyte shape and geometry via ERK signaling pathway: potential therapeutic implications in reversing cardiac remodeling?" Molecular and Cellular Biochemistry, vol. 297, no. 1-2, pp. 65-72, 2007.

[34] C. Pantos, V. Malliopoulou, I. Mourouzis et al., "Thyroxine pretreatment increases basal myocardial heat-shock protein 27 expression and accelerates translocation and phosphorylation of this protein upon ischaemia," European Journal of Pharmacology, vol. 478, no. 1, pp. 53-60, 2003.

[35] C. Pantos, V. Malliopoulou, I. Mourouzis et al., "Hyperthyroid hearts display a phenotype of cardioprotection against ischemic stress: a possible involvement of heat shock protein 70," Hormone and Metabolic Research, vol. 38, no. 5, pp. 308$313,2006$.

[36] C. I. Pantos, V. A. Malliopoulou, I. S. Mourouzis et al., "Longterm thyroxine administration protects the heart in a pattern similar to ischemic preconditioning," Thyroid, vol. 12, no. 4, pp. 325-329, 2002.

[37] A. Shulga, A. Blaesse, K. Kysenius et al., "Thyroxin regulates BDNF expression to promote survival of injured neurons," Molecular and Cellular Neuroscience, vol. 42, no. 4, pp. 408418, 2009.

[38] G. J. Kahaly and W. H. Dillmann, "Thyroid hormone action in the heart," Endocrine Reviews, vol. 26, no. 5, pp. 704-728, 2005.

[39] B. Biondi and D. S. Cooper, "The clinical significance of subclinical thyroid dysfunction," Endocrine Reviews, vol. 29, no. 1, pp. 76-131, 2008.

[40] I. Klein and K. Ojamaa, "Thyroid hormone and the cardiovascular system," The New England Journal of Medicine, vol. 344, no. 7, pp. 501-509, 2001.

[41] M. Gomberg-Maitland and W. H. Frishman, "Thyroid hormone and cardiovascular disease," American Heart Journal, vol. 135, no. 2, pp. 187-196, 1998.

[42] M. A. Hamilton, L. W. Stevenson, M. Luu, and J. A. Walden, "Altered thyroid hormone metabolism in advanced heart failure," Journal of the American College of Cardiology, vol. 16, no. 1, pp. 91-95, 1990.

[43] C. Opasich, F. Pacini, N. Ambrosino et al., "Sick euthyroid syndrome in patients with moderate-to-severe chronic heart failure," European Heart Journal, vol. 17, no. 12, pp. 18601866, 1996.

[44] A. Pingitore, P. Landi, M. C. Taddei, A. Ripoli, A. L'Abbate, and G. Iervasi, "Triiodothyronine levels for risk stratification of patients with chronic heart failure," American Journal of Medicine, vol. 118, no. 2, pp. 132-136, 2005.

[45] D. D. Ascheim and K. Hryniewicz, "Thyroid hormone metabolism in patients with congestive heart failure: the low triiodothyronine state," Thyroid, vol. 12, no. 6, pp. 511-515, 2002.

[46] L. Wartofsky and K. D. Burman, "Alterations in thyroid function in patients with systemic illness: the "euthyroid sick syndrome"'” Endocrine Reviews, vol. 3, no. 2, pp. 164-217, 1982.
[47] R. D. Utiger, "Altered thyroid function in nonthyroidal illness and surgery. To treat or not to treat?" The New England Journal of Medicine, vol. 333, no. 23, pp. 1562-1563, 1995.

[48] F. Forini, A. Paolicchi, T. Pizzorusso et al., "3,5,3'triiodothyronine deprivation affects phenotype and intracellular $\left[\mathrm{Ca}^{2+}\right]_{\mathrm{i}}$ of human cardiomyocytes in culture," Cardiovascular Research, vol. 51, no. 2, pp. 322-330, 2001.

[49] L. Friberg, S. Werner, G. Eggertsen, and S. Ahnve, "Rapid down-regulation of thyroid hormones in acute myocardial infarction: is it cardioprotective in patients with angina?" Archives of Internal Medicine, vol. 162, no. 12, pp. 1388-1394, 2002.

[50] E. Galli, A. Pingitore, and G. Iervasi, "The role of thyroid hormone in the pathophysiology of heart failure: clinical evidence," Heart Failure Reviews, vol. 15, no. 2, pp. 155-169, 2010.

[51] L. Ceremuzyński, A. Górecki, L. Czerwosz et al., "Low serum triiodothyronine in acute myocardial infarction indicates major heart injury," Kardiologia Polska, vol. 60, no. 5, pp. 468480, 2004.

[52] G. Kozdag, D. Ural, A. Vural et al., "Relation between free triiodothyronine/free thyroxine ratio, echocardiographic parameters and mortality in dilated cardiomyopathy," European Journal of Heart Failure, vol. 7, no. 1, pp. 113-118, 2005.

[53] G. Iervasi, A. Pingitore, P. Landi et al., "Low-T3 syndrome: a strong prognostic predictor of death in patients with heart disease," Circulation, vol. 107, no. 5, pp. 708-713, 2003.

[54] G. Iervasi, S. Molinaro, P. Landi et al., "Association between increased mortality and mild thyroid dysfunction in cardiac patients," Archives of Internal Medicine, vol. 167, no. 14, pp. 1526-1532, 2007.

[55] P. W. Ladenson, S. I. Sherman, K. L. Baughman, P. E. Ray, and A. M. Feldman, "Reversible alterations in myocardial gene expression in a young man with dilated cardiomyopathy and hypothyroidism," Proceedings of the National Academy of Sciences of the United States of America, vol. 89, no. 12, pp. 5251-5255, 1992.

[56] W. S. Colucci, "Molecular and cellular mechanisms of myocardial failure," The American Journal of Cardiology, vol. 80, no. 11A, pp. 15L-25L, 1997.

[57] W. I. Khalife, YI. D. Tang, J. A. Kuzman et al., "Treatment of subclinical hypothyroidism reverses ischemia and prevents myocyte loss and progressive LV dysfunction in hamsters with dilated cardiomyopathy," American Journal of Physiology, vol. 289, no. 6, pp. H2409-H2415, 2005.

[58] N. Tribulova, V. Knezl, A. Shainberg, S. Seki, and T. Soukup, "Thyroid hormones and cardiac arrhythmias," Vascular Pharmacology, vol. 52, no. 3-4, pp. 102-112, 2010.

[59] I. Klein and S. Danzi, "Thyroid disease and the heart," Circulation, vol. 116, no. 15, pp. 1725-1735, 2007.

[60] G. J. Kahaly, C. Kampmann, and S. Mohr-Kahaly, "Cardiovascular hemodynamics and exercise tolerance in thyroid disease," Thyroid, vol. 12, no. 6, pp. 473-481, 2002.

[61] B. Biondi, E. A. Palmieri, S. Fazio et al., "Endogenous subclinical hyperthyroidism affects quality of life and cardiac morphology and function in young and middle-aged patients," Journal of Clinical Endocrinology and Metabolism, vol. 85, no. 12, pp. 4701-4705, 2000.

[62] G. J. Kahaly, J. Nieswandt, S. Wagner, J. Schlegel, S. MohrKahaly, and G. Hommel, "Ineffective cardiorespiratory function in hyperthyroidism," Journal of Clinical Endocrinology and Metabolism, vol. 83, no. 11, pp. 4075-4078, 1998.

[63] L. W. Hu, L. A. Benvenuti, E. A. Liberti, M. S. Carneiro-Ramos, and M. L. M. Barreto-Chaves, "Thyroxine-induced cardiac 
hypertrophy: influence of adrenergic nervous system versus renin-angiotensin system on myocyte remodeling," American Journal of Physiology, vol. 285, no. 6, pp. R1473-R1480, 2003.

[64] S. P. Barry, S. M. Davidson, and P. A. Townsend, "Molecular regulation of cardiac hypertrophy," International Journal of Biochemistry and Cell Biology, vol. 40, no. 10, pp. 2023-2039, 2008.

[65] G. Kaminski, D. Michalkiewicz, K. Makowski et al., "Prospective echocardiographic evaluation of patients with endogenous subclinical hyperthyroidism and after restoring euthyroidism," Clinical Endocrinology, vol. 74, no. 4, pp. 501-507, 2011.

[66] R. M. Abdulrahman, V. Delgado, A. C. T. Ng et al., "Abnormal cardiac contractility in long-term exogenous subclinical hyperthyroid patients as demonstrated by two-dimensional echocardiography speckle tracking imaging," European Journal of Endocrinology, vol. 163, no. 3, pp. 435-441, 2010.

[67] B. Biondi, "Invited commentary: cardiovascular mortality in subclinical hyperthyroidism: an ongoing dilemma," European Journal of Endocrinology, vol. 162, no. 3, pp. 587-589, 2010.

[68] T. Vadiveloo, P. T. Donnan, L. Cochrane, and G. P. Leese, “The thyroid epidemiology, audit, and research study (TEARS): the natural history of endogenous subclinical hyperthyroidism," Journal of Clinical Endocrinology and Metabolism, vol. 96, no. 1, pp. E1-E8, 2011.

[69] J. V. Parle, P. Maisonneuve, M. C. Sheppard, P. Boyle, and J. A. Franklyn, "Prediction of all-cause and cardiovascular mortality in elderly people from one low serum thyrotropin result: a 10-year cohort study," The Lancet, vol. 358, no. 9285, pp. 861-865, 2001.

[70] F. Osman, M. D. Gammage, and J. A. Franklyn, "Hyperthyroidism and cardiovascular morbidity and mortality," Thyroid, vol. 12, no. 6, pp. 483-487, 2002.

[71] The Coronary Drug Project Research Group, “The coronary drug project. Findings leading to further modifications of its protocol with respect to dextrothyroxine," Journal of the American Medical Association, vol. 220, no. 7, pp. 996-1008, 1972.

[72] W. F. Young Jr., C. A. Gorman, N. S. Jiang, D. Machacek, and I. D. Hay, "L-thyroxine contamination of pharmaceutical D-thyroxine: probable cause of therapeutic effect," Clinical Pharmacology and Therapeutics, vol. 36, no. 6, pp. 781-787, 1984.

[73] M. A. Portman, A. Slee, A. K. Olson et al., "Triiodothyronine supplementation in infants and children undergoing cardiopulmonary bypass (TRICC): a multicenter placebocontrolled randomized trial: age analysis," Circulation, vol. 122, no. 11, supplement 1, pp. S224-S233, 2010.

[74] J. D. Klemperer, I. Klein, M. Gomez et al., "Thyroid hormone treatment after coronary-artery bypass surgery," The New England Journal of Medicine, vol. 333, no. 23, pp. 1522-1527, 1995.

[75] J. D. Klemperer, J. Zelano, R. E. Helm et al., “Triiodothyronine improves left ventricular function without oxygen wasting effects after global hypothermic ischemia," Journal of Thoracic and Cardiovascular Surgery, vol. 109, no. 3, pp. 457-465, 1995.

[76] A. Pingitore, E. Galli, A. Barison et al., "Acute effects of triiodothyronine $\left(T_{3}\right)$ replacement therapy in patients with chronic heart failure and low $-\mathrm{T}_{3}$ syndrome: a randomized, placebo-controlled study," Journal of Clinical Endocrinology and Metabolism, vol. 93, no. 4, pp. 1351-1358, 2008.

[77] F. S. Malik, M. R. Mehra, P. A. Uber, M. H. Park, R. L. Scott, and C. H. van Meter, "Intravenous thyroid hormone supplementation in heart failure with cardiogenic shock," Journal of Cardiac Failure, vol. 5, no. 1, pp. 31-37, 1999.

[78] M. A. Hamilton, L. W. Stevenson, G. C. Fonarow et al., "Safety and hemodynamic effects of intravenous triiodothyronine in advanced congestive heart failure," The American Journal of Cardiology, vol. 81, no. 4, pp. 443-447, 1998.

[79] P. Moruzzi, E. Doria, and P. G. Agostoni, "Medium-term effectiveness of L-thyroxine treatment in idiopathic dilated cardiomyopathy," American Journal of Medicine, vol. 101, no. 5, pp. 461-467, 1996.

[80] G. Iervasi, M. Emdin, R. M. P. Colzani et al., "Beneficial effects of long-term triiodothyronine (T3) infusion in patients with advanced heart failure and low T3 syndrome," in Proceedings of the 2nd International Congress on Heart Disease-New Trends in Research, Diagnosis and Treatment, A. Kimchi, Ed., pp. 549553, Medimond Medical Publications, Washington, DC, USA, 2001.

[81] M. G. Trivieri, G. Y. Oudit, R. Sah et al., "Cardiac-specific elevations in thyroid hormone enhance contractility and prevent pressure overload-induced cardiac dysfunction," Proceedings of the National Academy of Sciences of the United States of America, vol. 103, no. 15, pp. 6043-6048, 2006.

[82] D. D. Belke, B. Gloss, E. A. Swanson, and W. H. Dillmann, "Adeno-associated virus-mediated expression of thyroid hormone receptor isoforms- $\alpha 1$ and $-\beta 1$ improves contractile function in pressure overload-induced cardiac hypertrophy," Endocrinology, vol. 148, no. 6, pp. 2870-2877, 2007.

[83] P. Moruzzi, E. Doria, P. G. Agostoni, V. Capacchione, and P. Sganzerla, "Usefulness of L-thyroxine to improve cardiac and exercise performance in idiopathic dilated cardiomyopathy," The American Journal of Cardiology, vol. 73, no. 5, pp. 374378, 1994.

[84] H. Degens, A. J. Gilde, M. Lindhout, P. H. M. Willemsen, G. J. van der Vusse, and M. van Bilsen, "Functional and metabolic adaptation of the heart to prolonged thyroid hormone treatment," American Journal of Physiology, vol. 284, no. 1, pp. H108-H115, 2003.

[85] E. A. Boehm, B. E. Jones, G. K. Radda, R. L. Veech, and K. Clarke, "Increased uncoupling proteins and decreased efficiency in palmitate-perfused hyperthyroid rat heart," American Journal of Physiology, vol. 280, no. 3, pp. H977H983, 2001.

[86] G. D. Pennock, T. E. Raya, J. J. Bahl, S. Goldman, and E. Morkin, "Cardiac effects of 3,5-diiodothyropropionic acid, a thyroid hormone analog with inotropic selectivity," Journal of Pharmacology and Experimental Therapeutics, vol. 263, no. 1, pp. 163-169, 1992.

[87] X. Wang, W. Zheng, L. P. Christensen, and R. J. Tomanek, "DITPA stimulates bFGF, VEGF, angiopoietin, and Tie-2 and facilitates coronary arteriolar growth," American Journal of Physiology, vol. 284, no. 2, pp. H613-H618, 2003.

[88] E. Morkin, G. Pennock, P. H. Spooner, J. J. Bahl, K. Underhill Fox, and S. Goldman, "Pilot studies on the use of 3,5diiodothyropropionic acid, a thyroid hormone analog, in the treatment of congestive heart failure," Cardiology, vol. 97, no. 4, pp. 218-225, 2002.

[89] S. Goldman, M. McCarren, E. Morkin et al., "DITPA (3,5diiodothyropropionic acid), a thyroid hormone analog to treat heart failure: phase II trial veterans affairs cooperative study," Circulation, vol. 119, no. 24, pp. 3093-3100, 2009.

[90] A. Pingitore, G. Iervasi, and M. A. Gerdes, "Letter by Pingitore et al regarding article, "DITPA (3,5-diiodothyropropionic acid), a thyroid hormone analog to treat heart failure: phase 
II trial Veterans Affairs cooperative study"', Circulation, vol. 121, no. 10, e240, 2010.

[91] H. Mizuma, M. Murakami, and M. Mori, "Thyroid hormone activation in human vascular smooth muscle cells: expression of type II iodothyronine deiodinase," Circulation Research, vol. 88, no. 3, pp. 313-318, 2001.

[92] A. Colantuoni, P. L. Marchiafava, D. Lapi, F. S. Forini, and G. Iervasi, "Effects of tetraiodothyronine and triiodothyronine on hamster cheek pouch microcirculation," American Journal of Physiology, vol. 288, no. 4, pp. H1931-H1936, 2005.

[93] A. M. Gerdes and G. Iervasi, "Thyroid replacement therapy and heart failure," Circulation, vol. 122, no. 4, pp. 385-393, 2010.

[94] J. A. Ezekowitz, P. Kaul, J. A. Bakal, P. W. Armstrong, R. C. Welsh, and F. A. McAlister, "Declining in-hospital mortality and increasing heart failure incidence in elderly patients with first myocardial infarction," Journal of the American College of Cardiology, vol. 53, no. 1, pp. 13-20, 2009.

[95] T. M. Khumri, K. J. Reid, M. Kosiborod, J. A. Spertus, and M. L. Main, "Usefulness of left ventricular diastolic dysfunction as a predictor of one-year rehospitalization in survivors of acute myocardial infarction," The American Journal of Cardiology, vol. 103, no. 1, pp. 17-21, 2009. 


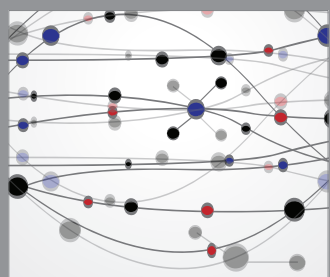

The Scientific World Journal
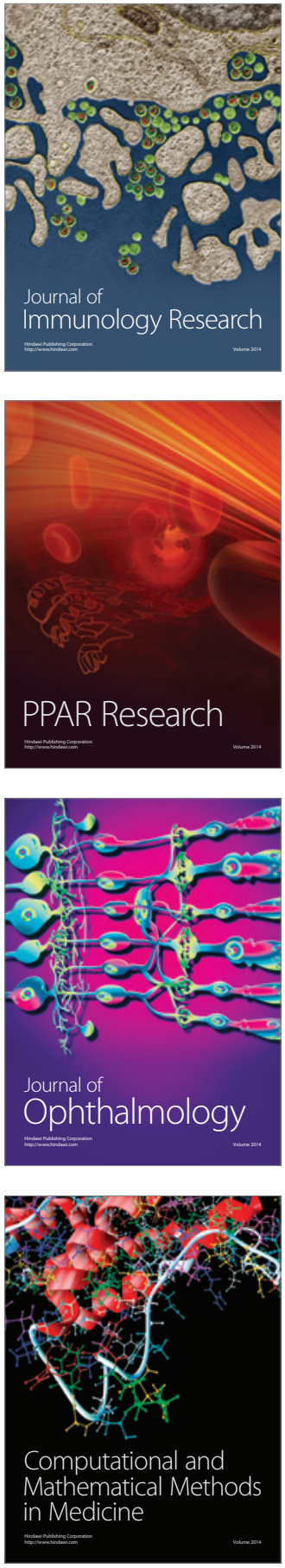

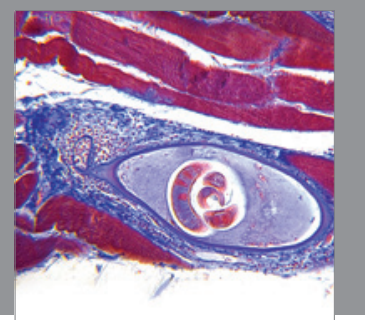

Gastroenterology

Research and Practice
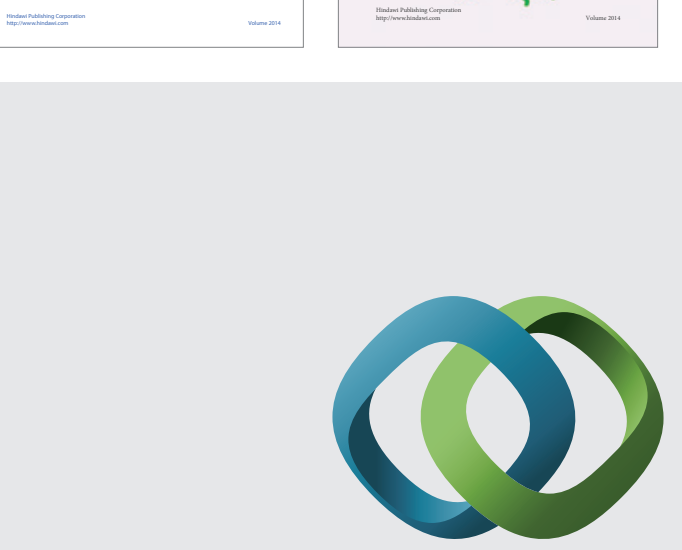

\section{Hindawi}

Submit your manuscripts at

http://www.hindawi.com
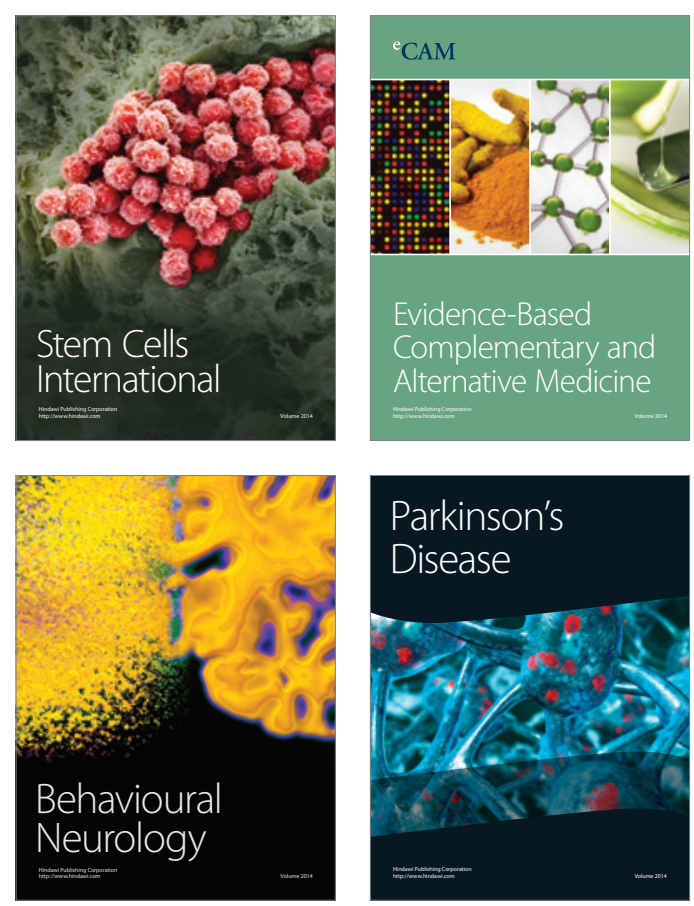

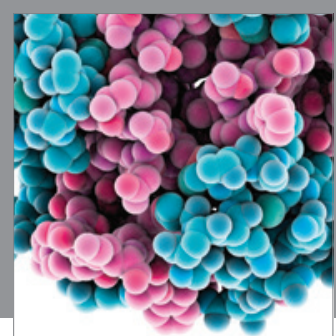

Journal of
Diabetes Research

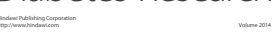

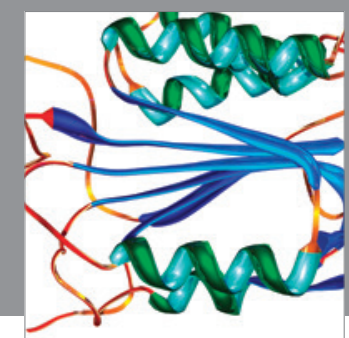

Disease Markers
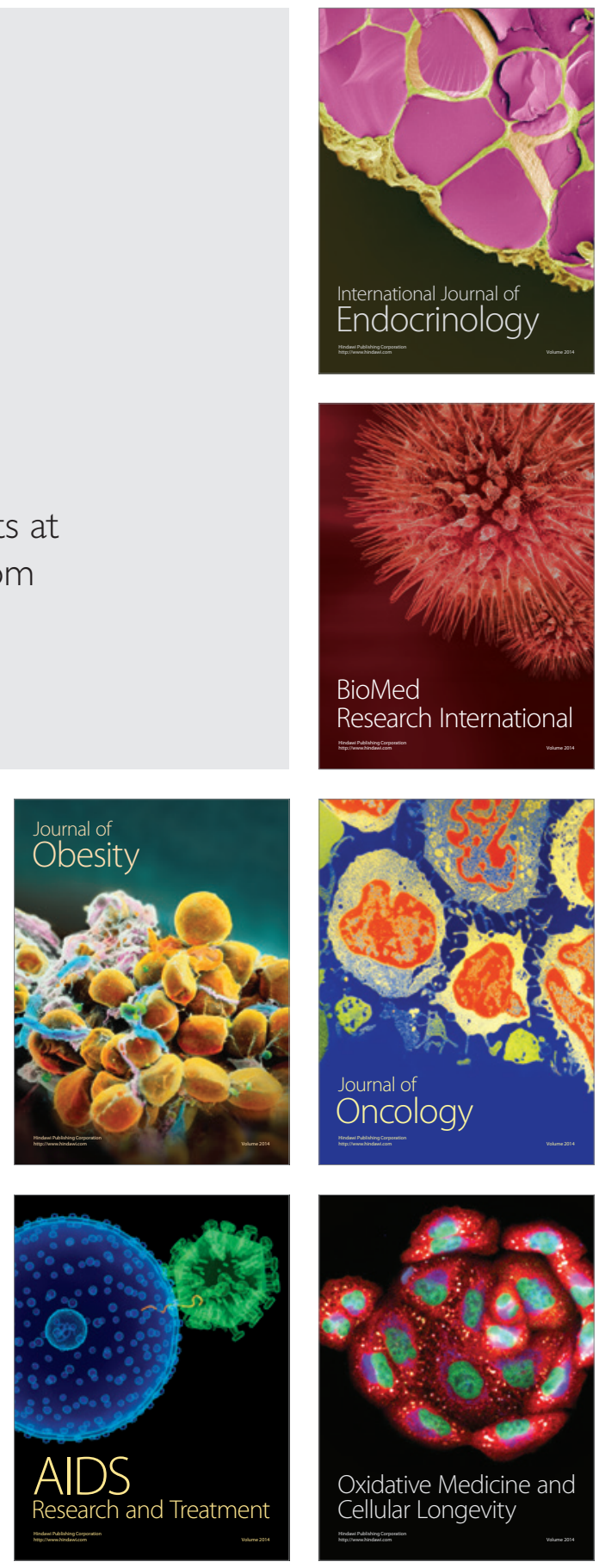